\title{
EDUCAÇÃO PARA A SAÚDE EM PROL DE UMA SOCIEDADE PREVENTIVA: REALIDADE ENTRE PROFESSORES MUNICIPAIS DO ENSINO FUNDAMENTAL DE SANTA MARIA, RS ${ }^{1}$.
}

\author{
Isis Samara Ruschel Pasquali
}

\author{
${ }^{1}$ Este artigo é resultado parcial da Tese de Doutorado do Programa de \\ Pós-Graduação em Educação em Ciências: Química da Vida e Saúde - PPGECQV/UFSM
}

\section{RESUMO}

O Planeta se apresenta em um momento muito frágil devido ao desequilíbrio generalizado em seus sistemas naturais, causado principalmente pelo estilo de vida humano: consumidor, egoísta e antropocêntrico. Hoje se sabe que a qualidade ambiental está diretamente relacionada à qualidade de vida humana, isto é, a vida humana tem uma boa qualidade quando seu entorno está em equilíbrio, mas em meio à poluição e à falta de higiene do ambiente, o homem terá como retorno a propagação de novas e velhas doenças que afetam sua saúde. Infelizmente não se percebe uma significativa alteração comportamental humana no sentido de frear a origem desse problema, que é a degradação do meio ambiente, pois muitos povos, como o brasileiro, apresentam atitudes remediadoras quando se trata de saúde. Essa realidade mostra a necessidade de uma educação voltada à compreensão da interação do homem com seu entorno, o que é tratado pela educação ambiental, mas também um ensino em saúde, que instrua o cidadão desde pequeno a ter hábitos saudáveis e preventivos em relação à saúde pessoal e coletiva. Ambas as linhas educativas (ambiental e em saúde) foram instituídas no Brasil pelo Ministério de Educação - MEC, ainda nos anos 90, a serem desenvolvidas como temas transversais em nível escolar, mas mesmo tendo uma crescente demanda de trabalhos voltados a educação ambiental, não se tem dados concretos sobre a interação dessa com o ensino em saúde e nem a realidade desse ensino no ambiente escolar. Com essa prerrogativa, o presente trabalho buscou conhecer a realidade do ensino de saúde no município de Santa Maria, RS, selecionando para a pesquisa as escolas municipais de educação fundamental do bairro Camobi, devido a heterogeneidade social de seus públicos. A investigação se deu através de um questionário que pretendeu averiguar a respeito da percepção dos docentes quanto ao seu papel em relação ao desenvolvimento de assuntos ligados a saúde e sua condição em atender as exigências do MEC sobre o mesmo. A pesquisa do tipo exploratória, com análise quali-quantitativa, envolveu 48 (quarenta e oito) professores e as 06 (seis) escolas representantes da parcela escolhida, com as quais se pretende manter contato e oferecer retorno que as auxilie na difícil tarefa de educar transversalmente o tema saúde em prol de uma sociedade preventiva.

Palavras-chave: Educação em Saúde, Educação Ambiental, PCNs, Temas Transversais. 


\section{ABSTRAT}

The planet is presented in a very fragile moment, due to the imbalance in their widespread natural systems, caused mainly by human lifestyle: consumer, selfish and anthropocentric. Today we know that environmental quality is directly related to the quality of human life, that is, human life has a good quality when its environment is in balance. But amid the pollution and the lack of environmental hygiene, the man will return to the spread of new and old diseases that affect their health. Unfortunately, there is not a significant change human behavior in order to stop the source of this problem, which is the degradation of the environment, for many people, such as Brazil, have remedial actions when it comes to health. Unfortunately, we not perceived a significant change human behavior in order to stop the source of this problem, which is the degradation of the environment, since many people, like brazilian, show remedial actions in relation to health. This situation shows the need for an education directed to the understanding of man's interaction with its environment, what is working for environmental education, and also the strengthening of health education, so that instruct the citizen early on to have healthy habits and preventive in relation to personal and collective health. Both educational lines (environmental and health) were introduced in Brazil by the Ministry of Education - MEC, even in 90"s, be developed as transverse themes at the school level. However, even though a growing demand for work oriented to environmental education, there is no concrete data on the interaction of this with health education, and not with the reality of teaching in the school environment. Therefore, this study sought to know the reality of health education in the municipality of Santa Maria, RS, selecting for the search the Camobi's schools of basic education, because your social heterogeneity. he study was conducted with application of a questionnaire, order to ascertain the perception of teachers about their role in the development of health-related issues, and your condition to answer the requirements of the MEC, about this. The research is exploratory type, with qualitative and quantitative analysis, and involved forty eight teachers, and representatives of the six schools selected portion, whom he intends to stay in contact, and provide feedback to assist in the difficult task of educating across the health issue in favor of a preventive society.

Key words: Health education, Environmental education, PCNs, Transversal Themes.

\section{INTRODUÇÃO}

O Planeta se apresenta em um momento muito frágil devido ao desequilíbrio generalizado em seus sistemas naturais, causado principalmente pelo estilo de vida humano que interfere, elimina e impacta componentes, seres vivos e seus habitats, para satisfazer cada vez mais sua busca pelo conforto, e sabe-se que tal fragilidade está afetando a qualidade de vida humana. Essa relação de simples causa e efeito, infelizmente, foi compreendida há muito pouco tempo e provavelmente por isso ainda pouco aceita ou percebida por todos, visto que, no geral, as atitudes humanas praticamente não sofreram alteração no sentido de preservar o meio ambiente (natural, construído, cultural ou de trabalho). Em vista desse contexto, a educação ambiental busca atingir todos os cidadãos, no intuito de sensibilizá-los para que tais atitudes, tão inconsequentes e impactantes, e ora tão rotineiras, tenham um fim ou, ao menos, uma regressão significante, mas parece que a percepção da maioria da população ainda desvincula a qualidade do ambiente com a qualidade de suas próprias vidas, por isso se faz necessário um ensino voltado a desenvolver os diversos assuntos que permeiam o tema sobre saúde humana juntamente com a 
educação ambiental, necessidade percebida e institucionalmente cobrada pelo Ministério da Educação no Brasil - MEC.

O conhecimento sobre diversos temas que envolvem o da saúde é essencial para que o indivíduo desenvolva hábitos básicos e rotineiros que permitirão ao mesmo manter uma vida adequada com boa qualidade e saúde, como: a higiene pessoal e do ambiente; a escolha por alimentos saudáveis, necessários e em quantidade adequadas; o efeito devastador das drogas e sua dependência; entre outros. O Sistema Brasileiro de Saúde se encontra em situação de sobrecarga, principalmente nos centros públicos de atendimento médico que, excluindo-se questões de cunho político, dentre os milhões de cidadãos que esperam atendimento, há um grande número que não necessitaria estar enfrentando tal situação se tivesse conhecimento e consciência plena sobre hábitos saudáveis de vida.

Para o MEC/Brasil, o conhecimento básico sobre si próprio e seu entorno, deve ser adquirido em fase de formação escolar, inclusive os relacionados à saúde, ética, cultura, consumo, entre outros, e de forma transversal ${ }^{1}$, perpassando por todas as áreas do conhecimento, o que permite ao educando o aprendizado dos assuntos tratados de forma interligada e não seccionada por áreas que não se correlacionam, de forma que ele seja capaz "de desenvolver o conhecimento ajustado de sim mesmo e de seu entorno, para posicionar-se de maneira crítica, responsável e construtiva nas diferentes situações sociais"².

Não somente por se tratar de assuntos sobre saúde, mas por esse (dever) ser desenvolvido de forma transversal, que o docente deve estar engajado e ter domínio da temática além de seus conteúdos programáticos, para que a mesma seja cumprida de maneira satisfatória. O próprio Ministério da Educação reconhece a complexa tarefa de educar assuntos que envolvam a formação e correção de hábitos, atitudes e concepções do cotidiano de crianças e adolescentes, de forma que tal assunto não seja tratado como uma nova disciplina, mas que seja colocado em discussão, incorporados aos conteúdos das áreas já existentes e ao trabalho habitual da escola, o que não é nada fácil de ser exercido.

Mas como o professor (pré)concebe essa atuação de forma transversal? Os educadores sentem-se preparados para assumir essa tarefa em relação ao tema transversal saúde?

Trata-se de questões urgentes, como assinalam os documentos que apresentam os PCNs, o que ressalta a importância da mediação de tais debates e a relevância da organização da escola com a participação integral do corpo docente.

Em vista disso, este artigo tem o objetivo de investigar os professores de 6ㅇ a 90 ano, do Ensino Fundamental da rede pública municipal de Camobi, Santa Maria, em relação a sua percepção quanto à existência de vínculos informacionais ou pedagógicos, entre suas áreas de atuação e os assuntos do tema transversal saúde, e se os mesmos percebem-se preparados para mediar de forma transversal o eixo temático da saúde.

A justificativa para tal investigação reside no fato de que o Ministério da Saúde brasileiro reconhece que a simples transmissão de informações sobre o funcionamento do corpo, sobre as particularidades das doenças, e sobre os hábitos de higiene não são suficientes para que os educandos desenvolvam atitudes de vida saudável, sendo necessário uma atuação educadora que leve em conta todos os aspectos envolvidos na formação de hábitos, atitudes e concepções de jovens em idade escolar, o que exige do professor engajamento e domínio da temática.

\footnotetext{
1 “O princípio da transversalidade e de transdisciplinaridade busca superar o conceito de disciplina. (...) busca-se uma intercomunicação entre as disciplinas, tratando efetivamente de um tema/objetivo comum (transversal)". Instituto Paulo Freire/Programa de Educação Continuada. Disponível em: http://www.inclusao.com.br/

${ }^{2}$ Trecho dos objetivos dos PCNs, para o ensino fundamental.
} 
Por reconhecer a real e crescente demanda de doenças relacionadas à falta de higiene, má alimentação e outras rotinas inadequadas desde a infância, o Estado também instituiu, nos últimos anos, a Política Nacional de Educação Permanente em Saúde ${ }^{3}$, mostrando a necessidade real e urgente do "desenvolvimento de ações e práticas de educação em saúde no âmbito escolar" ${ }^{4}$, face à orientação do Estado no sentido de instituir políticas de manutenção da saúde preventiva, em detrimento de uma mera política de saúde curativa ${ }^{5}$. Esse quadro reforça o papel da escola e dos professores como agentes da formação de indivíduos capazes de atuar ativamente na manutenção de sua saúde.

\section{METODOLOGIA}

Como sujeitos da pesquisa foram selecionados professores que atuam nas séries finais do ensino fundamental (60 ao 9o ano) da rede municipal de Camobi, Santa Maria/RS, constituindo um universo de 48 (quarenta e oito) professores, segundo informações recebidas pelas escolas locais. Esses professores representam as 06 (seis) escolas que totalizam a rede municipal de ensino fundamental/séries finais de Camobi, sendo elas: Vicente Farencena, Santa Helena, Renato Nocchi Zimmermann, Lívia Menna Barreto, Julio do Canto e Antônio Gonçalves do Amaral. As seis escolas serão identificadas na pesquisa, aleatoriamente, como escolas " $A$ ", " $B$ ", " $C$ ", " $D$ ", " $E$ " e " $F$ ". A escolha das mesmas se deve ao fato de possibilitar uma análise completa em um grupo específico, em um dos bairros mais populosos de Santa Maria, que apresenta como característica marcante uma grande diversidade social de seus alunos.

\section{Instrumentos e Procedimentos de Coleta de dados}

A coleta de dados se deu através de três etapas: etapa pré-formal, etapa 1 e etapa 2.

A etapa chamada de "pré-formal", primeira fase do trabalho, se estabeleceu através de uma investigação de estudos, pesquisas e demais levantamentos de dados - em livros, revistas, artigos, notícias entre outras - inerentes à temática saúde, no intuito de conhecer o que já havia de informação basicamente em relação à saúde no Brasil, ao desenvolvimento do tema saúde nas escolas, ao que é exigido em lei e sobre a opinião de pesquisadores e professores sobre o desenvolvimento do tema. Tal investigação permitiu selecionar o grupo de professores que seria pesquisado e os pontos de discussão que deveria fazer parte do instrumento de pesquisa, assim como os objetivos específicos - buscando pesquisar algo ainda sem dados precisos:

Etapa 1 - objetivou conhecer o sujeito da pesquisa. Cada escola foi visitada antecipadamente à aplicação da pesquisa. Em cada uma delas foi firmado contato com uma pessoa que se responsabilizou em mediar a pesquisa entre os professores (diretor(a), vice ou supervisor(a) pedagógico(a)); e, através de uma conversa informal com cada representante,

\footnotetext{
${ }^{3}$ A Política Nacional de Educação Permanente em Saúde (PNEPS) é uma proposta de ação estratégica que visa a contribuir para transformar e qualificar as práticas de saúde, e inclui todo o pessoal incumbido da educação para a saúde: médicos, enfermeiros, pessoal administrativo, professores, entre outros.

${ }^{4}$ Texto da Portaria Interministerial no 749, de 13 de Maio de 2005, que Constitui a Câmara Intersetorial para a elaboração de diretrizes com a finalidade de subsidiar a Política Nacional de Educação em Saúde na Escola.

${ }^{5} \mathrm{O}$ Brasil "mostra uma perspectiva de saúde curativa que, culturalmente, faz com que os indivíduos brasileiros se preocupem com a saúde somente depois de ficarem doentes" (Zils, 2009).
} 
objetivou-se levantar alguns dados básicos, além de transmitir a importância de tal pesquisa e da participação de todos os professores que trabalham nas séries finais do ensino fundamental.

Esta etapa foi importante e muito favorável, pois além de permitir um primeiro contato com as escolas, alvo da pesquisa, e a investida na sensibilização quanto à importância de uma participação maciça dos professores envolvidos, possibilitou observar que o instrumento de pesquisa, para ter o máximo de fidelidade, deve ser: de rápida análise por parte dos pesquisados; que permita respostas curtas, de preferência objetivas; e que o pesquisador retorne a análise dos dados obtidos, aos participantes da mesma. Também foi relatado o receio com pesquisas na forma de entrevista gravada, pelo tempo e possibilidade de ser identificado (dependendo do teor da mesma). Também foi possível levantar o número total de professores com atuação no campo de interesse do estudo e as disciplinas comuns à todas as escolas.

Assim, esta fase norteou o instrumento de pesquisa, que foi aplicado na etapa posterior.

Etapa 2 - o levantamento e análise dos dados obtidos a partir da "conversa" mantida na etapa 1, norteou a configuração de um questionário como instrumento de pesquisa, que foi aplicado aos professores.

O questionário continha oito questões, sendo sete questões objetivas e uma questão aberta que possibilitaria expor a percepção real do docente frente a sua prática e o compromisso com o ensino para a saúde.

A pesquisa foi do tipo exploratória, com avaliação quali-quantitativa, de forma a permitir uma análise sobre a percepção dos professores investigados, de maneira que venham a esclarecer as inquietações levantadas por este estudo.

\section{RESULTADOS E DISCUSSÃO}

\section{Fase pré-formal}

Nesse levantamento bibliográfico foram coletadas informações pertinentes que delinearam a pesquisa. Entre elas as seguintes citações, separadas por tópicos de discussão:

\section{- O Brasil apresenta a característica remediadora em saúde}

O Brasil "mostra uma perspectiva de saúde curativa que, culturalmente, faz com que os indivíduos brasileiros se preocupem com a saúde somente depois de ficarem doentes" (ZILS, 2009, p.04).

"A falta de higiene e de cuidados essenciais com a limpeza dos dentes e de toda a cavidade bucal é a principal responsável por doenças que vão desde uma simples gengivite até tumores. (...) Infeç̧ões crônicas da gengiva, por exemplo, podem danificar fígado e rins. (...) agentes nocivos podem se alojar no coração e piorar o quadro, provocando até a morte" (OLIVEIRA, 2011, p.01).

Segundo o guia de doenças infecciosas e parasitárias da FUNASA ${ }^{6}$, algumas doenças infecciosas se devem somente ao fato de falta de higiene pessoal e do ambiente. A fundação aponta como uma das principais medidas de controle para esses casos "desenvolver atividades de educação em saúde, particularmente com relação a hábitos pessoais de higiene, particularmente o de lavar as mãos antes das refeições e o uso de calçados". (FUNASA, 2000, p.30).

\footnotetext{
${ }^{6}$ Fundação Nacional de Saúde, do Ministério da Saúde, do Governo Federal, Brasil.
} 


\section{- A importância da educação em saúde na infância e adolescência}

Ao se agrupar aos Temas Transversais questões ligadas à saúde, essa abordagem vem contribuir para a garantia da qualidade de vida e saúde da sociedade. A escola tem um papel decisivo na valorização de comportamentos relativos à saúde, pois a infância e adolescência são épocas decisivas na construção de condutas (MEC/SEF, 1998, p. 257).

\section{- A importância da transversalidade na educação para a saúde}

Sob a perspectiva do processo saúde/doença, as suas múltiplas dimensões, por si só, explicam a opção de caracterizar a educação para a Saúde como um tema transversal do currículo. Dessa forma, somente a participação das diferentes áreas, cada qual enfocando conhecimentos específicos à sua competência, é possível garantir que os alunos construam uma visão ampla do que é saúde (ZILS, 2009).

\section{- A realidade pedagógica do docente para educar em saúde}

Pesquisas realizadas por autores como Oliveira e Silva (1990), Conceição (1994), e Fernandes, Rocha e Souza (2005), concluem que os professores não são adequadamente preparados para trabalhar com o ensino de saúde, e que seu processo de formação, em tal área, é falho; e geralmente centrado em práticas pedagógicas desvinculadas da realidade.

Há, também, pesquisas que constatam uma visão claramente fragmentada de ensino, entre os profissionais da área, como o trabalho de Santos (2007), que verificou a existência de uma concepção especialista nas escolas, através da qual todos consideram que o mais habilitado para o trabalho com saúde, meio ambiente, ecologia, entre outros é o professor de Ciências, demonstrando uma contradição em relação à complexidade que caracteriza a temática.

Como já descrito, as questões levantadas na fase "pré-formal", citadas de forma sucinta nos tópicos acima, delinearam o trabalho, principalmente em relação aos objetivos e a definição dos sujeitos da pesquisa, que se sucedeu nas seguintes etapas.

\section{Etapa 1}

Essa etapa contou com visita e conversa informal com representantes das escolas alvo da pesquisa, o que permitiu, em primeiro lugar, perceber que a heterogeneidade não ocorre somente entre os educandos, mas também entre as escolas, mesmo sendo essas todas municipais de ensino fundamental - isso foi constatado principalmente através da estrutura física das mesmas e a disponibilidade de áreas disciplinares diferenciadas, como informática e religião, que por não serem contempladas por todas as escolas, não participaram deste estudo, de forma que esses dados não viessem a interferir no contexto geral.

Assim, para fim desta pesquisa, serão levadas em consideração as oito áreas disciplinares que se fazem presente em praticamente ${ }^{7}$ todas as escolas, que são: História, Geografia, Português, Inglês, Matemática, Ciências, Educação Física e Artes. Importa saber que em algumas dessas escolas, alguns profissionais desenvolvem mais de uma disciplina e que em outras existe mais de um profissional para a mesma disciplina.

\footnotetext{
${ }^{7}$ Somente uma delas não possuía professor de educação física de forma efetiva em seu quadro profissional, mas como a disciplina está diretamente ligada à área de saúde, é importante que se conheça a concepção desses profissionais sobre o assunto. A disciplina de artes também não faz parte do contexto educacional em uma das escolas, mas por saúde ser um tema transversal, que permeia todos os campos educacionais, a participação de cinco profissionais da área são de extrema importância para a pesquisa, por isso serão mantidas na análise escolar.
} 
Conforme dados passados por cada representante das seis escolas visitadas, o bairro de Camobi, em Santa Maria/RS, possui um total de quarenta e oito professores municipais que atuam nas séries finais do ensino fundamental, nas oito áreas de interesse deste estudo.

Como resultado da Etapa 1, foi montado um questionário contendo oito questões, sendo sete objetivas e uma aberta. O questionário foi arquitetado para abranger assuntos que, em poucas questões, fosse possível alcançar os objetivos propostos por esta pesquisa.

\section{Etapa 2}

Todos os professores que atuam do 60 ao 90 ano da rede pública de ensino fundamental nas escolas do bairro Camobi, de Santa Maria, foram convidados a responder o questionário; no entanto, dos 48 (quarenta e oito) professores, apenas 42 (quarenta e dois) responderam, totalizando $87,5 \%$ dos docentes representantes do universo selecionado, sendo esta uma amostra de representação satisfatória para a pesquisa.

A avaliação dos dados coletados através da aplicação do questionário se deu através de duas análise diferenciadas: 1- a comparação entre a realidade das escolas; e 2- a concepção dos professores das séries finais do ensino fundamental de Camobi, Santa Maria, a respeito das questões inquiridas pela pesquisa, através da análise do somatório das respostas.

Em relação a análise 1 serão mostrados dados referentes à percepção do conjunto de professores de cada escola, para possibilitar a observação de existência ou não de diferencial entre as instituições, onde as mesmas serão tratadas como Escola $A, B, C, D, E$ e F, de forma a não expor as particularidade de cada uma.

\section{Resultados da análise - etapa 2}

Os dados resultantes da apreciação dos questionários serão apresentados em grupamentos de questões que tratem de assuntos vinculados, permitindo desenvolver análise e discussão sobre os temas que possibilitarão alcançar os objetivos propostos por esta pesquisa.

Com a questão 1 buscou-se apreciar o grau de conhecimento dos docentes sobre os PCNs, já que vamos tratar desse assunto durante toda a pesquisa.

\begin{tabular}{|c|c|c|c|c|c|c|c|c|c|}
\hline & & \multicolumn{6}{|c|}{ ESCOLAS } & \multirow[b]{2}{*}{ TOTAL } & \multirow[b]{2}{*}{$\%$} \\
\hline QUESTÃO & ALTERNATIVAS & A & B & $\mathrm{C}$ & $\mathrm{D}$ & $\mathrm{E}$ & $\mathrm{F}$ & & \\
\hline \multirow{3}{*}{$\begin{array}{l}\text { QUESTÃO 1- Como } \\
\text { você define seu } \\
\text { conhecimento sobre } \\
\text { os temas transversais } \\
\text { constantes nos PCNs? }\end{array}$} & Pouco & - & - & 01 & - & 04 & - & 05 & $11,90 \%$ \\
\hline & Razoável & 03 & 08 & 05 & 02 & 03 & 07 & 28 & $66,67 \%$ \\
\hline & Muito Bom & 04 & - & 02 & 02 & - & 01 & 09 & $21,43 \%$ \\
\hline
\end{tabular}

Figura 1 - apresenta as respostas referentes à primeira pergunta do questionário.

É possível observar que a grande maioria dos professores se coloca na condição de conhecer "razoavelmente" tais temas, há escolas em que $100 \%$ deles, ou quase isso. Mas podemos observar que na escola " $A$ " mais de $50 \%(57,14 \%)$ se percebem com um conhecimento muito bom sobre os temas transversais, mas em outra, a escola " $E$ ", essa realidade é exatamente 
ao contrário, por $57,14 \%$ dos docentes se perceberem com pouco conhecimento sobre os mesmos temas.

Essa constatação nos permite identificar a existência de uma grande heterogeneidade no nível de conhecimento sobre os temas transversais entre uma escola e outra. Importa observar que são escolas do mesmo bairro, todas municipais, diferenciando-se, no entanto, por seus Planos Político Pedagógicos - PPPs, devido a autonomia que as escolas têm para desenvolvê-los e a pluralidade das práticas educacionais entre os profissionais, o que vai de encontro com o que afirma Santos (2007), quando observa que as práticas educacionais são bastante diversas.

Quanto à representação da concepção do universo pesquisado, nota-se que penas $21,43 \%$ dos professores possuem um conhecimento muito bom sobre os temas transversais constantes nos Parâmetros Curriculares Nacionais, sendo que a grande maioria, $78,57 \%$, conhece pouco ou razoavelmente tais temas, nos levando a perceber que deve haver muita dificuldade em desenvolver os temas transversais de forma concreta nessas escolas, pois não é possível educar com eficiência, sobre assuntos que não se tem um bom conhecimento.

As questão 2 e 3 , já se remetem especificamente ao tema transversal de saúde, com as quais tenta-se observar a percepção dos docentes quanto a existência ou não de vínculos entre suas áreas de atuação e a temática de saúde e se percebem-se em condições de educar de forma transversal tal assunto.

Para essas questões, obtiveram-se os seguintes dados:

\begin{tabular}{|c|c|c|c|c|c|c|c|c|c|}
\hline \multirow[b]{2}{*}{ QUESTÕES } & \multirow[b]{2}{*}{ ALTERNATIVAS } & \multicolumn{6}{|c|}{ ESCOLAS } & \multirow[b]{2}{*}{ TOTAL } & \multirow[b]{2}{*}{$\%$} \\
\hline & & A & B & C & $D$ & $E$ & $\mathrm{~F}$ & & \\
\hline \multirow{3}{*}{$\begin{array}{l}\text { QUESTÃO } 2-\text { Você } \\
\text { percebe a existência de } \\
\text { vínculos entre sua(s) } \\
\text { disciplina(s) e o tema } \\
\text { transversal de Educação } \\
\text { para a Saúde? }\end{array}$} & Não & - & 01 & 01 & - & 01 & - & 03 & $7,14 \%$ \\
\hline & Um Pouco & 02 & 04 & 03 & 02 & 05 & 07 & 23 & $54,76 \%$ \\
\hline & Bastante & 05 & 03 & 04 & 02 & 01 & 01 & 16 & $38,10 \%$ \\
\hline \multirow{3}{*}{$\begin{array}{l}\text { QUESTÃO 3- Você se } \\
\text { percebe em condições } \\
\text { de dar conta do encargo } \\
\text { de educar de maneira } \\
\text { transversal o assunto } \\
\text { Saúde? }\end{array}$} & Não & 01 & 01 & 01 & - & 02 & - & 05 & $11,90 \%$ \\
\hline & Um Pouco & 02 & 06 & 06 & 02 & 05 & 06 & 27 & $64,29 \%$ \\
\hline & Bastante & 04 & 01 & 01 & 02 & - & 02 & 10 & $23,81 \%$ \\
\hline
\end{tabular}

Figura 2 - apresenta as respostas referentes à segunda e à terceira pergunta do questionário.

A análise dessas duas questões em conjunto, permite identificar as seguintes particularidades, entre outras:

- mesmo somente 03 professores não percebendo vínculo entre suas áreas de atuação e os temas que envolvem saúde, 05 deles não se percebem em condições de educar de forma transversal tais temas - de $7,14 \%$ para $11,9 \%$;

- embora $38,10 \%$ dos docentes pesquisados perceberem bastante vínculo entre a(s) disciplina(s) que trabalha e o tema transversal de saúde, quase $40 \%$ desses $(37,51 \%)$ não se percebem com bastante condição de educar de forma transversal tal temática - representando $14,29 \%$ do universo da pesquisa - sendo que um deles ainda afirma não se sentir em condições de educar em saúde, mesmo percebendo bastante vínculo entre essa área e sua especialidade; 
- a grande maioria dos professores percebe pouco vínculo entre a temática de saúde e sua(s) área(s) educacional(is) (54,76\%), e em pouca condição de dar conta do encargo de educar transversalmente sobre os assuntos relacionados à saúde;

- pode ser percebido, novamente, as diferenças perceptivas entre a escola " $A$ " e a escola " $E$ " - mais de $71 \%$ dos docentes da escola " $A$ " percebem bastante vínculo entre suas matérias e os temas de saúde e mais de $57 \%$ do total dessa escola, se conceitua com bastante condição de educar transversalmente tais assuntos; enquanto que na escola " $E$ ", somente $14,29 \%$ percebem existir bastante vínculo entre assuntos que trabalham e os de saúde, mas nenhum se concebe com bastante condição de educar transversamente os mesmos.

Esses dados são preocupantes, pois, no geral, mostram que menos de $24 \%$ dos docentes das séries finais do ensino fundamental de Camobi, concebem-se em condições de cumprir as exigências do MEC quanto à sua atuação de forma transversal sobre o tema de saúde - vale destacar aqui, que em torno de $5 \%$ desses professores alegam terem tido experiências extraclasse que os aproximou da área da saúde, a exemplo de um professor de matemática, que é, também, bacharel em enfermagem, deixando a porcentagem real com exatamente $19,05 \%$ da mostra da pesquisa.

Felizmente, para a educação, apenas 05 professores se julgam sem condições de educar para a saúde, juntamente com os assuntos que desenvolvem em aula. Os cinco profissionais lecionam na área de: matemática, inglês, educação física e artes.

Mas à que motivo os docentes atribuem sua posição quanto ao grau que julgam ter em relação a sua condição de dar conta do encargo de educar de maneira transversal sobre o tema da saúde? No intuito de encontrar respostas para essa questão, foi formulada a quarta pergunta do questionário, que de forma aberta, possibilitou a livre e real expressão da opinião, e até inquietação, do respondente frente a sua atuação pedagógica na área de estudo.

Sob a ótica da análise de conteúdos, os termos-chave mais recorrentes foram agrupados por proximidade de assunto, o que possibilitou separar as respostas abertas em 06 grupos: tenho formação em área afim; tenho formação em área não-afim (referente a respostas como: minha formação possibilita o trabalho somente com alguns temas de saúde; falta de conhecimento; despreparo); atualizo-me, tenho experiência (estudo e leitura individual; experiência por anos de trabalho ou por contato com trabalhos em saúde; em curso de formação continuada ${ }^{9}$ ); falta-me estudo ou atualização para trabalhar de maneira transversal o tema saúde; tenho alta demanda de outros assuntos (não tenho tempo, tenho carga horária elevada); e não respondeu.

Para analisar as respostas dos docentes em relação ao questionamento no 4 , se faz necessário observar a questão 3, pois a resposta aberta se refere justamente ao que foi apontado pela questão 3, portanto, para efeito de facilitar a análise, os dados da questão 3 serão novamente apresentados, mas agora para uma análise com diferenciada.

Observemos a tabela abaixo:

\begin{tabular}{|c|c|c|c|c|c|c|c|c|c|}
\hline & & \multicolumn{6}{|c|}{ ESCOLAS } & & \\
\hline QUESTÕES & ALTERNATIVAS & A & B & C & D & $E$ & $\mathrm{~F}$ & TOTAL & $\%$ \\
\hline $\begin{array}{c}\text { QUESTÃO } 3 \text { - Você se } \\
\text { percebe em }\end{array}$ & Não & 01 & 01 & 01 & - & 02 & - & 05 & $11,90 \%$ \\
\hline conta do encargo de & Um Pouco & 02 & 06 & 06 & 02 & 05 & 06 & 27 & $64,29 \%$ \\
\hline
\end{tabular}




\begin{tabular}{|c|c|c|c|c|c|c|c|c|c|}
\hline $\begin{array}{c}\text { educar de maneira } \\
\text { transversal o assunto } \\
\text { Saúde? }\end{array}$ & Bastante & 04 & 01 & 01 & 02 & - & 02 & 10 & $23,81 \%$ \\
\hline \multirow{6}{*}{$\begin{array}{l}\text { QUESTÃO 4- A que } \\
\text { motivo você atribuí } \\
\text { sua posição na } \\
\text { resposta acima? } \\
\text { (referência a questão } \\
\text { 3) }\end{array}$} & $\begin{array}{l}\text { Formação em Área } \\
\text { afim* }\end{array}$ & 02 & 01 & 01 & 01 & - & 02 & 07 & $16,67 \%$ \\
\hline & $\begin{array}{c}\text { Formação em área } \\
\text { não-afim* }\end{array}$ & 01 & 03 & 03 & 01 & 04 & 01 & 13 & $30,95 \%$ \\
\hline & $\begin{array}{c}\text { Atualiza-se/ tem } \\
\text { experiência }\end{array}$ & 02 & - & 01 & 01 & - & 01 & 05 & $11,90 \%$ \\
\hline & $\begin{array}{c}\text { Falta de estudo ou } \\
\text { atualização }\end{array}$ & 01 & 03 & - & - & - & 02 & 06 & $14,29 \%$ \\
\hline & $\begin{array}{c}\text { Alta demanda de } \\
\text { outros assuntos }\end{array}$ & - & - & 02 & - & 02 & - & 04 & $9,52 \%$ \\
\hline & Não respondeu & 01 & 01 & 01 & 01 & 01 & 02 & 07 & $16,67 \%$ \\
\hline
\end{tabular}

Figura 3 - apresenta as respostas referentes à terceira e à quarta pergunta do questionário.

* Para auxiliar na análise da percepção dos docentes, este trabalho considerou - levando em consideração assuntos desenvolvidos na base de formação de docentes - o que segue:

- áreas de formação afim com a área de saúde $\rightarrow$ serão consideradas as áreas que diretamente tem assuntos relacionados ao tema de saúde dentro de seus conteúdos normais, como ciências e educação física;

- área não-afim com a área de saúde $\rightarrow$ serão consideradas as áreas que não possuem "normalmente", em seus conteúdos didáticos, temas diretamente relacionados à saúde, como as demais disciplinas aqui tratadas: matemática, artes, história, geografia e as línguas portuguesa e inglesa.

Ao se analisar as duas questões conjuntamente, é possível perceber que apesar de 10 (dez) docentes afirmarem ter "bastante" condição de abordar o tema transversal de saúde e 07 (sete) alegarem ter formação em área afim, vale saber que somente 05 (cinco) docentes relatam ter bastante condição de tal tarefa, por possuírem formação acadêmica em área afim; portanto, outros 05 (cinco) percebem-se em condições de trabalhar transversalmente com temas de saúde, mesmo não atribuindo a isso sua formação e sim ao estudo, leitura ou formação continuada apenas um atribuiu a experiência de ter trabalhado com um grupo de saúde - mostrando que há possibilidade de se cumprir tal exigência do MEC, se houver o reconhecimento da necessidade de um docente se manter atualizado.

Outro ponto de grande relevância - apresentado através da descrição das áreas de formação dos docentes envolvidos, pela importância que se faz tal conhecimento, mesmo não sendo o foco desta análise - é que, dos 05 (cinco) docentes que afirmam ter bastante condição de desenvolver transversalmente assuntos que envolvem saúde, por se perceberem com formação em área afim: 02 (dois) são professores de Geografia; 01 (um) leciona matemática, mas relata também ter formação em Enfermagem; 01 (um) é da área de Educação Física; e 01 (um) é de Ciências. A análise de fato nos faz perceber que se os dados de outros trabalhos estão corretos, e certamente estão, de que em muitas escolas quando existe educação em saúde de forma transversal, a mesma é atribuída principalmente ao professor de Ciências, a prática dessa temática está necessitando de muita atenção. Vale destacar aqui a opinião de um professor de Educação Física que, mesmo tendo formação em área afim com a de saúde, afirma não ter condições de trabalhar 
de forma transversal sobre o tema, pois, como ele ressalta, "trabalho com educação e não sou profissional da saúde".

Essa questão foi importante para a análise geral por ser do tipo aberta, como já relatado, o que permitiu a expressão real do profissional inquirido, possibilitando conhecer a concepção geral dos docentes que não se perceberem com bastante condição de educar em saúde de forma transversal. Em relação aos que alegam não possuírem tal condição, ficou claro que se deve ao fato de excluírem-se da descrita responsabilidade por não terem formação na área de saúde, através de alegações do tipo: "não tenho formação para tal", "não tenho conhecimento", e a já citada "não sou profissional da saúde", confirmando dados de outras pesquisas pré-existentes. Já para os que alegam ter pouca condição de educar em saúde, a maioria é da opinião que tal condição ocorre por falta de atualização pessoal ou por possuírem "jornada de trabalho"/"quantidade horas-aula" elevadas e por "existem outros temas a tratar"; uma professora de história e geografia atribuiu, ainda, à sua pouca condição de educar de maneira transversal o assunto saúde, ao fato de que o mesmo "é pouco trabalhado e divulgado nas escolas na hora do planejamento dos conteúdos". Infelizmente sete professores, dos que participaram da pesquisa, se abstiveram de responder a questão 4 , somando um total de $16,67 \%$ da amplitude amostral.

Dando sequência à análise do questionário, a questão 5 interroga se o profissional aborda os temas de saúde em suas aulas. Essa questão possibilita aumentar o conhecimento do quadro real que está se formando a cada exposição da opinião dos professores. Para melhor comparação e análise dos dados, a questão 5 também será apresentada juntamente com a questão 3 , conforme a figura abaixo:

\begin{tabular}{|c|c|c|c|c|c|c|c|c|c|}
\hline & & \multicolumn{6}{|c|}{ ESCOLAS } & \multirow[b]{2}{*}{ TOTAL } & \multirow[b]{2}{*}{$\%$} \\
\hline QUESTÕES & ALTERNATIVAS & $A$ & B & $\mathrm{C}$ & $\mathrm{D}$ & $E$ & $\mathrm{~F}$ & & \\
\hline \multirow{3}{*}{$\begin{array}{l}\text { QUESTÃO 3- Você se } \\
\text { percebe em condições } \\
\text { de dar conta do } \\
\text { encargo de educar de } \\
\text { maneira transversal o } \\
\text { assunto Saúde? }\end{array}$} & Não & 01 & 01 & 01 & - & 02 & - & 05 & $11,90 \%$ \\
\hline & Um Pouco & 02 & 06 & 06 & 02 & 05 & 06 & 27 & $64,29 \%$ \\
\hline & Bastante & 04 & 01 & 01 & 02 & - & 02 & 10 & $23,81 \%$ \\
\hline \multirow{3}{*}{$\begin{array}{c}\text { QUESTÃO 5- Você } \\
\text { aborda os temas de } \\
\text { saúde no decorrer de } \\
\text { suas aulas? }\end{array}$} & Não & - & 01 & - & - & 02 & 01 & 04 & $9,52 \%$ \\
\hline & Um Pouco & 03 & 04 & 06 & 02 & 05 & 06 & 26 & $61,90 \%$ \\
\hline & Bastante & 04 & 03 & 02 & 02 & - & 01 & 12 & $28,57 \%$ \\
\hline
\end{tabular}

Figura 4 - apresenta as respostas referentes à terceira e à quinta pergunta do questionário.

Felizmente, apenas 04 (quatro) professores alegam não abordar o tema de saúde em suas aulas, mas é possível perceber que não são os mesmos que não se percebem em condições de desenvolver tal tema em sala. $O$ docente da escola " $A$ " e o da escola " $C$ ", que alegam não se perceber em condições de abordar o tema de saúde, afirmam que trabalham um pouco sobre o mesmo. Da mesma forma, um profissional da escola " $E$ " que se percebe com "um pouco" de condição para trabalhar com esse tema, afirma na questão 5 que não o faz, é um professor de Ciências - este caso será descrito melhor juntamente com a análise da próxima questão que indaga a forma de abordagem.

Outro significativo ganho para a educação é percebido em relação a quantidade de abordagem do tema, se observarmos que $23,81 \%$ dos profissionais se perceberem com bastante 
condição de educar de forma transversal assuntos ligados a saúde, mas são $28,57 \%$ que abordam bastante esses assuntos em suas aulas, isto é 4,76\% (quatro professores) dos entrevistados afirmam que mesmo percebendo que possuem somente um pouco de condição em educar sobre saúde, abordam bastante esse tema em suas aulas - dois deles são professores de Língua Inglesa, que alegando buscar o conhecimento de forma individual através de estudo sobre o tema; e os outros dois são professores de Ciências que abordam muito sobre saúde em aula, mas não se percebem com muita condição para o mesmo devido, segundo um deles, a falta de atualização.

Os dados apresentados na figura 5, abaixo, se referem mais especificamente à questão 6 , mas traz novamente os dados da questão 5 para possibilitar a observação das formas de abordagem do tema saúde, quando existente, em relação a freqüência com que são abordadas. $A$ questão 6 pretendeu conhecer de que forma esses docentes abordam tal tema, para analisar se o tipo de abordagem sugerida por ele é próxima a transversalidade exigida pelo MEC.

\begin{tabular}{|c|c|c|c|c|c|c|c|c|c|}
\hline & & & & & & & & & \\
\hline QUESTÕES & ALTERNATIVAS & A & B & $\mathrm{C}$ & $\mathrm{D}$ & $\mathrm{E}$ & $\mathrm{F}$ & TOTAL & $\%$ \\
\hline QUESTÃO 5 - Você & Não & - & 01 & - & - & 02 & 01 & 04 & $9,52 \%$ \\
\hline aborda os temas de & Um Pouco & 03 & 04 & 06 & 02 & 05 & 06 & 26 & $61,90 \%$ \\
\hline suas aulas? & Bastante & 04 & 03 & 02 & 02 & - & 01 & 12 & $28,57 \%$ \\
\hline & Conteúdo em aula & 02 & 02 & 02 & - & - & 03 & 09 & $21,43 \%$ \\
\hline & $\begin{array}{c}\text { Pesquisa e } \\
\text { Trabalho escolar }\end{array}$ & 02 & 01 & 03 & 01 & - & 01 & 08 & $19,05 \%$ \\
\hline $\begin{array}{l}\text { QUESTÃO } 6 \text { - De que } \\
\text { forma esse tema é }\end{array}$ & $\begin{array}{l}\text { Palestra e/ou } \\
\text { projeto da escola }\end{array}$ & 02 & 02 & 02 & - & 02 & 03 & 11 & $26,19 \%$ \\
\hline $\begin{array}{l}\text { trabalhado com os } \\
\text { alunos? }\end{array}$ & $\begin{array}{c}\text { Pesquisa e } \\
\text { Palestra }\end{array}$ & - & 02 & - & 02 & 02 & - & 06 & $14,29 \%$ \\
\hline & $\begin{array}{c}\text { Não trabalha ou só } \\
\text { tira dúvida }\end{array}$ & - & 01 & - & - & 03 & 01 & 05 & $11,90 \%$ \\
\hline & Todas respostas & 01 & - & 01 & 01 & - & - & 03 & $7,14 \%$ \\
\hline
\end{tabular}

Figura 5 - apresenta as respostas referentes à quinta e à sexta pergunta do questionário.

Ao se observar as alternativas de resposta, indicadas no questionário, é possível perceber que somente a primeira "conteúdo em aula" refere-se a algo desenvolvido pelo professor, enquanto que as demais são desenvolvidas por outros (alunos ou palestrantes) ou não são desenvolvidas. Isso expõe uma grande preocupação, a de que somente 09 (nove) professores trabalham ou parecem trabalhar de forma próxima a transversalidade exigida pelo MEC. Podemos considerar nesse somatório, mais 03 (três) docentes que afirmam trabalhar de todas as formas sugeridas no questionário, portanto, parece também desenvolverem o tema juntamente com seus conteúdos programáticos conforme previsto pelos PCNs, mesmo assim totalizam $28,57 \%$ dos representantes da pesquisa. Essa percentagem fecharia com os professores que afirmam desenvolver bastante o tema saúde, mas não é a realidade, a maioria desses aborda através de palestras e pedindo trabalhos ou pesquisa para os alunos. Ao se refletir mais profundamente sobre isso, nota-se que é bem provável que os docentes não saibam o que seja um trabalho transversal e que não há um projeto escolar para isso, mostrando que não cumprem o que é exigido pelo Ministério da Educação desde os anos 90. 
Preocupante também é perceber que a grande maioria $(26,19 \%)$ contrata um palestrante para ministrar uma explicação única e pontual sobre um assunto específico, outros 19,05\% cobram pesquisa ou trabalho escolar sem envolver o assunto em suas aulas e 14,29\% abordam o tema através de palestra e ou pesquisa extra-classe, totalizando $59,53 \%$ dos profissionais de educação, ao menos a nível municipal do bairro Camobi/SM, abordam o tema saúde em atividades extras, fora do desenvolvimento da teoria em sala de aula, apontando para uma atuação esporádica, com pouca chance do aluno aprender verdadeiramente sobre o que foi abordado ou pesquisado.

Ainda é possível notar que o número de professores que não trabalham com o tema aumentou de 04 (questão 5) para 05 (questão 6), pois "tirar dúvidas" não é abordar um pouco o tema na aula, conforme um professor da Escola "E" alegou, o que também possibilita averiguar que mais de $40 \%$ dos docentes dessa escola não desenvolvem os temas de saúde no decorrer de suas aulas, mas, dos quase $60 \%$ restantes, nenhum aborda o tema com seus conteúdos em aula, o fazem através de pesquisa, trabalho escolar e palestra.

A questão 6 mostra que quando o professor alega trabalhar o tema saúde, não o faz de forma transversal. Como já foi mencionado, isso se estabelece possivelmente por o mesmo não ter formação ou preparação pós-formação para trabalhar de forma transversal, o tema saúde ou qualquer outro tema. Assim, a questão 7 propôs levantar exatamente esses dados: qual a porcentagem de professores que receberam preparação para trabalhar transversalmente o tema saúde.

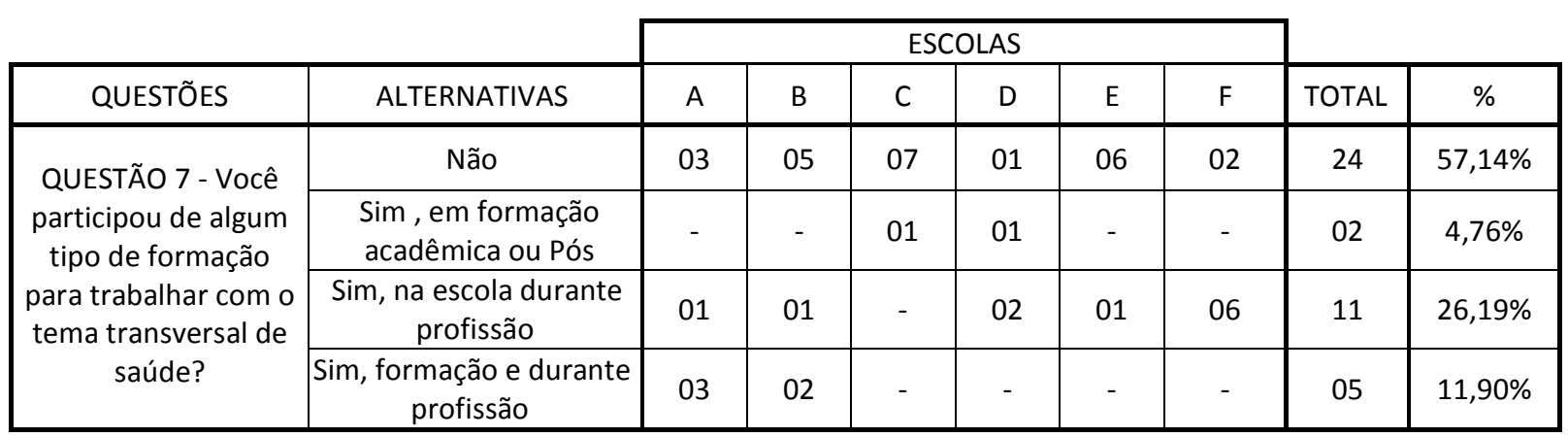

Figura 6 - apresenta as respostas referentes à sétima pergunta do questionário.

A análise dos dados adquiridos através das respostas da questão 7, possibilitou comprovar dados de alegações e declarações existentes em outros trabalhos, que afirmam ser a falta de preparo do docente uma das maiores causas, se não a maior, em não haver um desenvolvimento do tema transversal de saúde de maneira satisfatória no âmbito escolar, pois 57, $14 \%$ afirmaram não ter participado de nenhum tipo de formação para trabalhar com o tema saúde de forma transversal, mostrando que não houve um verdadeiro apoio do MEC na formação desses profissionais, apesar de exigir tal atuação deles, ou que grande parte das escolas não está tendo a conduta de proporcionar e exigir do profissional da educação sua formação continuada.

Nesse sentido é possível ao menos se questionar sobre tal conduta, quando se observa na figura 6 que apenas 01 (uma) escola não apresenta profissionais que receberam algum tipo de atualização na área. As outras 05 (cinco) escolas, apesar de poucos, apresentam profissionais com formação durante a profissão sobre saúde, apontando uma possível escolha do profissional, isto é, será que o fato de não haver muitos profissionais atualizados em saúde, seja por não haver interesse por parte deles? Quando se faz esse questionamento e se remete ao que foi respondido 
na questão 4, se percebe que a questão da "pré-concepção" dos docentes em não se julgarem responsáveis por desenvolver assuntos que não façam parte direta de sua formação acadêmica básica, parece ser uma realidade que interfere na conduta de educar para a saúde - lembrando as pesquisas já citadas que descrevem a percepção dos professores quanto a esse quesito, quando alegam que a educação em saúde, nas escolas, é percebida como atividade quase que exclusiva do professor de ciências, e por não se julgarem responsáveis pela mesma, as demais disciplinas não a desenvolvem.

Finalizando com a questão 8, objetivou-se apenas esclarecer se os impasses em não desenvolver adequadamente o tema transversal saúde na escola se deve ao fato do mesmo tratar de assuntos relacionados a saúde ou a problemática se estende também aos demais temais, pela questão da transversalidade com que devem ser abordados. Assim, a figura 7 apresenta dos dados da questão 8 em comparação com a questão 7 , pois procurar avaliar se há ligação também com a formação ou atualização de cada um.:

\begin{tabular}{|c|c|c|c|c|c|c|c|c|c|}
\hline & & \multicolumn{6}{|c|}{ ESCOLAS } & \multirow[b]{2}{*}{ TOTAL } & \multirow[b]{2}{*}{$\%$} \\
\hline QUESTÕES & ALTERNATIVAS & A & B & C & D & $\mathrm{E}$ & $\mathrm{F}$ & & \\
\hline \multirow{4}{*}{$\begin{array}{l}\text { QUESTÃO } 7 \text { - Você } \\
\text { participou de algum } \\
\text { tipo de formação para } \\
\text { trabalhar com o tema } \\
\text { transversal de saúde? }\end{array}$} & Não & 03 & 05 & 07 & 01 & 06 & 02 & 24 & $57,14 \%$ \\
\hline & $\begin{array}{l}\text { Sim, em formação } \\
\text { acadêmica ou Pós }\end{array}$ & - & - & 01 & 01 & - & - & 02 & $4,76 \%$ \\
\hline & $\begin{array}{c}\text { Sim, na escola } \\
\text { durante profissão }\end{array}$ & 01 & 01 & - & 02 & 01 & 06 & 11 & $26,19 \%$ \\
\hline & $\begin{array}{l}\text { Sim, formação e } \\
\text { durante profissão }\end{array}$ & 03 & 02 & - & - & - & - & 05 & $11,90 \%$ \\
\hline \multirow{3}{*}{$\begin{array}{l}\text { QUESTÃO } 8 \text { - Você se } \\
\text { percebe preparado } \\
\text { para tender às } \\
\text { exigências do MEC, } \\
\text { quanto ao ensino dos } \\
\text { diferentes temas } \\
\text { transversais? }\end{array}$} & Não & - & 01 & 01 & - & 06 & 01 & 09 & $21,43 \%$ \\
\hline & Um Pouco & 04 & 06 & 07 & 02 & 01 & 07 & 27 & $64,29 \%$ \\
\hline & Bastante & 03 & 01 & - & 02 & - & - & 06 & $14,29 \%$ \\
\hline
\end{tabular}

Figura 7 - apresenta as respostas referentes à sétima e à oitava pergunta do questionário.

A análise da última questão do instrumento da pesquisa apurar o quanto os docentes se percebem preparados para atender às exigências do MEC, quanto ao ensino dos diferentes temas transversais, não apenas o de saúde, mostrando que apenas $14,29 \%$ deles percebem-se com bastante condição para tal. Analisando juntamente com as respostas à questão 7 , podemos ver que dos 06 (seis) professores que se enquadram bastante aptos todos tiveram algum tipo de formação ou atualização relacionadas a transversalidade (pelo menos com o tema saúde). Os que se julgam com um pouco de preparo mostram que não se deve por formação/atualização, mas uma busca pessoal possivelmente. O compensador é ver que dos $57,14 \%$ que afirmam não ter participado de nenhuma formação para trabalhar com os temas que envolvem saúde, somente $21,43 \%$ alegam não se perceber preparado para atender ao MEC sobre nenhum dos temas transversais, mostrando que $35,71 \%$ recebeu alguma formação para trabalhar outros temas ou, o que parece ser mais provável avaliando-se os relatos da questão 4, é que esses docentes buscam conhecimento de forma particular, mostrando-se uma esperança no sentido de possibilidade de melhoria sobre as questões abordadas nessa pesquisa. 


\section{PASQUALI, vol.(5), n5, p. 1115 - 1131, 2012. Monografias Ambientais issN: 2236-1308}

\section{CONCLUSÃO}

A análise dos dados dessa pesquisa possibilitou perceber que a grande maioria dos professores não tem um conhecimento muito bom sobre os temas transversais, nem se percebe em plenas condições de educar de forma transversal sobre saúde ou mesmo sobre os demais temas transversais, não se sentindo bem preparada para tal. É possível averiguar também que não só entre professores, ou áreas de formação, mas entre as escolas de um mesmo bairro há uma significativa desconexão em relação a percepção de preparo que os docentes tem de si próprios sobre o trabalho com os temas transversais, principalmente os relacionados a saúde. Dois pontos principais foram identificados como os principais responsáveis por essa realidade: a falta de atualização profissional e de apoio e engajamento da escola nesse processo.

Foi possível perceber que há entre docentes do Ensino Fundamental da Rede Municipal, no mínimo, carência de formação ou de preparo no cumprimento às exigências do MEC. Em 2000 o próprio MEC apontou "uma enorme distância entre o perfil de professor que a realidade atual exige e o perfil de professor que a realidade até agora criou", denotando a carência de ações de formação para esse profissional, no sentido também de permitir sua aptidão ao ensino transversal dos novos temas dos PCNs (BRASIL, 2000).

A outra questão, que se refere ao engajamento da direção escolar, deve-se a inclusão ou não dos temas transversais no plano político pedagógico da escola e/ou o apoio institucional aos professores para que essa atividade seja cumprida. Duas explanações em resposta aberta, mostram claramente essa importância da intervenção escolar, observe:

- Situação 1 - a já citada professora de História e Geografia, diz que ter só um pouco de condições de trabalhar com os temas de saúde, pois "é pouco trabalhado e divulgado nas escolas na hora do planejamento dos conteúdos";

- Situação 2 - uma professora de Arte diz possuir um pouco de condição para educar em saúde, devido a "condições da escola em propiciar as atividades interdisciplinares".

Como é possível observar, um profissional de área não-afim diretamente, mas que estuda muito as questões envolvendo homem e ambiente, não se percebe com bastante condição do trabalho com temas de saúde, pois não há o engajamento da escola, como ocorre na situação 2 , onde um profissional, alheio a formação das ciências naturais, acredita ter condições, embora poucas, desse encargo, pois tem o engajamento da escola para tal.

Também foi possível perceber a existência de pré-concepções dos professores a cerca de sua formação e da dos colegas, no sentido de se isentar da responsabilidade caso não seja assunto de sua área de formação, confirmando dados de trabalhos que abordam o mesmo tema.

Assim, o que se pode afirmar é que o tema transversal saúde, embora fundamental na formação do cidadão, por possibilitar conhecimentos básicos, do cotidiano, mas que salvam vidas, não é abordado de forma satisfatória pelas escolas de ensino fundamental como prevê o MEC, pelo menos nas municipais do bairro Camobi em Santa Maria, RS, e isso deve ser mudado. Deve haver apoio e exigência por parte das escolas e do próprio Ministério da Educação para que os professores recebam formação continuada, atualização, dessa forma é possível cobrar o que se institui em Lei e é possível mudar pré-concepções errôneas e persistentes, do contrário, a qualidade de vida relacionada à existência de saúde do indivíduo, do cidadão, continuará decaindo, principalmente para os menos afortunados. 
Este trabalho pretende continuar com a apreciação do questionário através de uma segunda fase, onde as respostas serão analisadas e comparadas de acordo com a formação básica de cada professor.

\section{REFERÊNCIAS BIBLIOGRÁFICAS}

ARAÚJO, Ulisses Ferreira. Apresentação à edição brasileira. In: BUSQUETS, Maria. Temas Transversais em Educação: bases para uma formação integral. 6. ed. São Paulo : Ática, 2000.

AREDES, Alaíde Pereira J. Educação Continuada: melhoria da prática de ensino dos professores das escolas municipais e estaduais em Ivinhema, MS. In: CONGRESSO BRASILEIRO DE EXTENSÃO UNIVERSITÁRIA, 2., 2004, Belo Horizonte. Anais... Belo Horizonte: UFMG - Universidade Federal de Minas Gerais, 2004.

AUSUBEL, D. Aquisição e retenção de conhecimentos: uma perspectiva cognitiva. Lisboa: Plátano, 2003.

BRASIL. Ministério da Saúde. Política Nacional de Educação Permanente em Saúde. Brasília: Ministério da Saúde, 2009.

BRASIL. Ministério da Saúde. A promoção da saúde no contexto escolar. Informes Técnicos Institucionais. Revista de Saúde Pública, São Paulo: USP, v.36, n.2, p.533-535, 2002.

BRASIL. Ministério da Educação e do Desporto. Conselho Nacional de Educação. Câmara da Educação Básica. Resolução n. 02, de 07 abril de 1998. Institui as Diretrizes Curriculares Nacionais para o Ensino Fundamental. Diário Oficial da União. Brasília, 1998.

BRASIL. Secretaria de Educação Fundamental. Parâmetros Curriculares Nacionais - introdução aos Parâmetros Curriculares Nacionais. Brasília: MEC/SEF, 1997.

CONCEIÇÃO, José A. Nigro. Saúde Escolar: a criança, a vida e a escola. São Paulo: Sarvier, 1994.

CORRÊA, Carmen Izaura Molina. Análise da Participação de uma Escola Pública na Educação Sexual dos seus Alunos. 2003. Dissertação (Mestrado) - Faculdade de Filosofia e Ciências, UNESP. Marilia: UNESP, 2003.

FERNANDES, Marcos Henrique; ROCHA, Vera; SOUZA, Djanira. Concepção sobre Saúde do Escolar entre Professores do Ensino Fundamental (1a a 4ạ séries). História, Ciências, Saúde - Manguinhos, Rio de Janeiro, v.12, n.2. 2005.

FREIRE, Paulo. Pedagogia do Oprimido. 17. ed. Rio de Janeiro: Paz e Terra, 1987.

FUNASA. Doenças Infecciosas e Parasitárias: aspectos clínicos, de vigilância epidemiológica e medidas de controle - guia de bolso / elaborado por Gerson Oliveira Pena [et al]. 2. ed. Brasília : Ministério da Saúde : Fundação Nacional de Saúde, 2000.

GALLO, Sílvio. Conhecimento, Transversalidade e Educação: para além da interdisciplinaridade. (Coleção Canto Literário). São Paulo: UNESP, 2007. Disponível em: < http://www.cedap.assis.unesp.br/cantolibertario/textos/0119.html>. Acesso em: 22 mai. 2011.

GIL, Antonio Carlos. Métodos e técnicas de pesquisa social. São Paulo: Atlas, 1999.

INSTITUTO PAULO FREIRE. Inter-Transdisciplinaridade e Transversalidade. Programa de Educação Continuada. Sem data. Disponível em: $<$ http://www.inclusao.com.br/ projeto_textos_48.htm>. Acesso em: 21 jun. 2011. 
MIRANDA, Maria Inês Ferreira de. et al. Em busca da definição de pautas atuais para o delineamento de estudos sobre a saúde da criança e do adolescente em idade escolar. Revista latino-americana de enfermagem, Ribeirão Preto, v. 8, n. 6, p. 83-90, dez. 2000.

MONEGO, Estelamaris; JARDIM, Paulo César Veiga. Determinantes de risco para doenças cardiovasculares em escolares. Arquivos da Sociedade Brasileira de Cardiologia, São Paulo, v.87, n.1, 2006. Disponível em: <http://www.scielo.br/pdf/abc/v87n1/a06v87n1.pdf>. Acesso em: 22 jun. 2011.

MORIN, Edgar. A cabeça bem-feita: repensar a reforma, reformar o pensamento. 3.ed. Rio de Janeiro: Bertrand Brasil, 2001.

NONOSE, Eliana Roldão dos Santos, BRAGA, Tânia Moron Saes. Formação do Professor para Atuar com Saúde/Doença na Escola. In: CONGRESSO NACIONAL DE EDUCAÇÃO, 8., 2008, Curitiba-PR. Anais... Curitiba: PUC-PR, 2008. Disponível em: <http://www.pucpr.br/eventos/ educere/educere2008/anais/pdf/407_455.pdf>. Acesso em: 17 mai. 2011.

OLIVEIRA, Cecília L.; FISBERG, Mauro. Obesidade na Infância e Adolescência: uma verdadeira epidemia. Arquivos Brasileiros de Endocrinologia \& Metabologia, Rio de Janeiro, v. 47 n.2, 2003.

OLIVEIRA, Eulina. Da Incômoda Afta ao Temido Câncer. Revista Viva Saúde. Ed. On-line, artigo 11215-1, 2011. Disponível em: http://revistavivasaude.uol.com.br/saude-nutricao/0/artigo11215-1.asp. Acesso em 29 jul 2011.

OLIVEIRA, Maria Lúcia; SILVA, Maria Teresa Alves. da. Educação em Saúde: repensando a formação de professores. Revista Brasileira de Saúde Escolar, Campinas, v. 1, n. 2, p. 3-20, 1990.

RIZZINI, Irene, et al. Adolescentes brasileiros, mídia e novas tecnologias. ALCEU - Revista de Comunicação, Cultura e Política. Rio de Janeiro: PUC, v.6, n.11, p. 41 a 63, 2005.

SANTOS, Kátia Ferreira dos; BÓGUS, Cláudia Maria. A Percepção de Educadores sobre a Escola Promotora de Saúde: um estudo de caso. Revista Brasileira de Crescimento e Desenvolvimento Humano. São Paulo: USP, v.17, n.3, p. 123-133, 2007.

TRUJILLO, Victor. Pesquisa de Mercado Qualitativa e Quantitativa. São Paulo: Scortecci, 2001.

YUS, Rafael. Temas Transversais: em busca de uma nova escola. Porto Alegre: ArtMed, 1998.

ZILS, A. do A., et all. Educação em Saúde no Contexto Escolar. Editor coletivo de textos da UFRGS Psicoeduc, Porto Alegre, 2009. Disponível em:

<http://www6.ufrgs.br/psicoeduc/wiki/index.php/EDUCA\%C3\%87\%C3\%830_EM_SA\%C3\%9ADE_NO_CONT EXTO_ESCOLAR>. Acesso em: 03 jun 2011. 